\title{
Mental size scaling examined
}

\author{
DEREK BESNER and MAX COLTHEART \\ Reading University, Whiteknights, Reading, RG6 2AL, England
}

\begin{abstract}
Observers made same-different shape judgments of stimuli that were identical in shape and size, different in shape but not in size, or differed in relative size along a number of steps for both same- and different-shaped forms. "Same" judgment RTs increased monotonically with increases in the magnitude of the relative size difference. In contrast, "different" judgment RTs were unaffected by changes in relative size. A second experiment in which stimulus presentation was successive rather than simultaneous yielded essentially the same results. Consideration was given to a dual- process model in which a time-consuming analog process normalizes stimuli that are size discrepant prior to a comparison stage that is operative for those structures responsible for "same" decisions but not for "different" judgments. Some evidence that seems inconsistent with a normalization process which operates prior to contact with memory was discussed, and an alternative explanation in which the early detection of a size difference causes changes in decision criteria was suggested.
\end{abstract}

A familiar problem in visual pattern recognition concerns the manner in which an observer is able to ignore differences in irrelevant stimulus properties, e.g., orientation or size, when attempting to determine that two stimuli are instances of the same experimenterdefined category. One line of evidence indicates that under certain circumstances subjects may employ a strategy of mentally rotating into congruence stimuli that differ in orientation prior to judging whether they have the same shape (Shepard \& Metzler, 1971; Taylor, 1972).

Given that rotation can be utilized as a preprocessing stratagem, it is possible that analogous routines of a continuous nature may exist for other kinds of tasks that are thought to require preprocessing. A possible candidate task is one that involves same-different shape judgments of stimuli which may sometimes differ (irrelevantly) in size. Posner $(1969,1973)$ and Posner and Mitchell (1967) have suggested that shape matching of different-sized stimuli may require a visual process of an analog nature ("normalization") that equates stimuli for size prior to the operation of those processes normally used for shape comparisons. Supportive evidence for this analog size normalization hypothesis stems from experiments which demonstrate that matching times for different-size same-shape stimuli are slower than for same-size same-shape stimuli (Corcoran \& Besner, 1975; Posner \& Mitchell, 1967).

The results of these experiments cannot, however, be zonsidered as compelling evidence for the existence of a normalization process. Both experiments employed only one level of size difference; consequently, it is possible to argue that the observed time difference

We thank Ian Dennis for writing the computer programs that generated the random forms. Reprints can be obtained from Derek Besner, Department of Psychology, University of Reading, Building 3, Earley Gate, Whiteknights, Reading, England RG6 2AL. reflects a qualitatively different matching procedure from that involved in comparing identically sized stimuli. The latter may be compared by matching templates; by contrast, the presence of a size difference may incapacitate a template matching procedure since the templates will no longer overlap spatially. This may force a match based on a size-free structural description in which the time it takes to construct such a representation may be represented by a constant added to the time normally associated with matching same-sized stimuli. If this were the case, then varying relative size in a number of steps would produce an RT function that would be flat across the range of relative size differences, but some time constant $t$ longer than same-sized shape judgments. When such an experiment was performed (Sekuler \& Nash, 1972), reaction time over the range of size differences was found to be a monotonically increasing function, at least for "same" judgments. This result appears to rule out a level of analysis that uses as its datum a size-free structural description.

A remaining problem in the Sekuler and Nash (1972) study is that no statistical analysis was possible for the "different" judgment RTs, and a visual inspection of the data reveals little evidence for an increasing function with a slope identical to that observed for "same" judgments. Other experiments with letters, geometric forms, words, and nonwords have failed to find any significant effect of differences in relative size on "different" judgments (Besner \& Coltheart, 1974, Note 1). If normalization is an early process that operates prior to the comparison stage, then it would be reasonable to expect that normalizing the representation should incur equal time costs for both "same" and "different" decisions.

Besner and Coltheart's experiments, however, as well as the Sekuler and Nash study, are open to the objection that their stimulus materials are easily named, and it 

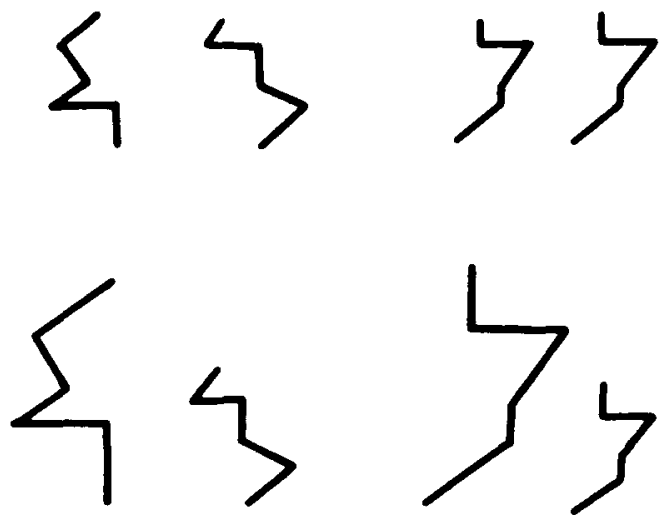

Figure 1. Some examples of the stimulus forms. Forms 1 and 3 require a "different" response, Forms 2 and 4 a "same" response.

has been argued that "different" judgments may often be based on nominal comparisons (Posner \& Mitchell, 1967). The logic of such a possibility follows from the fact that an analysis based on visual characteristics such as shape is sufficient for a correct "same" response, though not for a "different" judgment, because different shapes may share a common name (e.g., Aa). If visual and name comparisons are parallel operations, but visual comparisons are faster, then "same" judgments may be based on the completion of the faster process, while a "differ" judgment must await the outcome of the slower nominal comparison. If subjects make "different" judgments on a nominal criterion, then the fact that size has little observable effect may be explained by supposing that names are represented in a phonological code and, hence, contain no visual information. This argument receives some support from Corcoran and Besner's (1975) finding that letter pairs which are only nominally equivalent show no effect of relative size manipulations.

In the experiments reported here, therfore, an attempt was made to insure that comparisons were based solely on visual criteria. To this end, a computer program generated random patterns of sufficient complexity such that it appeared unlikely that a naming strategy could be successfully employed.

\section{EXPERIMENT I}

\section{Method}

Stimulus materials. The stimuli were computer-generated stick figures, each consisting of five line segments. The line segments were arranged such that each segment was joined to the end of another segment at one of three possible angles, and such that the figures remained open. "Different" stimuli were generated in such a fashion that the stimuli differed on a constant number of line segments. Some examples of the stimulus forms can be seen in Figure 1.

Three different figure sizes were generated by varying the length of the line segments in three steps. A standard size was labeled 100 for convenience and reduced twice in steps of $20 \%$. This procedure generated a total of six paired combina tions, counting left-right and right-left pairs as one combination These pairs were: $100 / 100,100 / 80,100 / 60,80 / 80,80 / 60$, and $60 / 60$; the approximate visual angle subtended by these pair: was, respectively, $1.83 \times .61,1.68 \times .61,1.53 \times .61,1.53 \times .46$ $1.37 \times .46$, and $1.22 \times .31 \mathrm{deg}$.

The stimuli, presented simultaneously in pairs spaced ap proximately $1.25 \mathrm{~cm}$ apart, were sampled with replacement from a pool of approximately 2,500 stimuli. Presentation of same-size stimuli was equally probable to that of different-sized stimulus pairs, and presentation of same-shaped pairs was equally prob. able to that of different-shaped pairs.

Subjects. The subjects were three males and three females who were either staff members or graduate students in the Department of Psychology at Reading University. All had previous experience with same-different RT tasks, and all served without pay.

Procedure. Subjects were seated in a darkened room at a table facing a CRT slaved to a PDP-12 computer. A small panel in front of the subject contained three buttons, two of which were response keys operated by the left and right index fingers, while the third key was controlled by the right thumb and initiated each trial.

At the start of a trial, a fixation point consisting of a small $x$ appeared on the CRT. Depressing the starting key terminated the fixation point; $500 \mathrm{msec}$ later a pair of random forms appeared, one to each side of the fixation point position. The display was terminated when the subject made a response. One second later the fixation point reappeared and the next trial began as soon as the subject pressed the start key.

The subjects were instructed to respond "same" if the figures were the same shape irrespective of size, and "different" if the figures had different shapes. They were informed of what constituted the stimulus population, response probabilities, number of practice trials, and the total number of trials. Speed was re quested, but at the same time subjects were cautioned to try and keep their error rate below $10 \%$. All subjects responded "same" with their preferred hand and "different" with their nonpreferred hand.

During a session each subject saw a different random series of 380 stimuli, the first 20 of which served as practice. The subjects were run individually for a total of four sessions, one each day for 4 consecutive days.

\section{Results}

The data from Session 1 (lost due to human error), the practice trials of Sessions 2, 3, and 4, and those trials on which errors were committed were excluded from the analysis. The data from the remaining trials can be seen in Table 1 .

Mean RTs for Sessions 2, 3, and 4 were submitted to an analysis of variance in which the respective factors were Size Levels, Type of Response, Sessions, and Ss. The analysis indicated that the main effects were all significant, that Sessions did not interact with any of the factors, and that the interaction of Size by Type of Response judgment was significant $[F(5,25)=23.02$, $\left.\mathrm{p}<.01, \mathrm{MS}_{\mathrm{e}}=244\right]$. A subsequent test for the simple main effects of Size at the level of the "different" response indicated that changes in relative size had no observable effect $(\mathrm{F}<1)$.

\section{EXPERIMENT II}

The purpose of the second experiment was primarily 
Table 1

Mean Reaction Times and Error Rates According to Conditions

\begin{tabular}{|c|c|c|c|c|c|c|c|c|c|c|c|c|}
\hline Subjects & $100 / 100$ & $\tau E$ & $100 / 80$ & $\mathscr{C}_{C}$ & $100 / 60$ & $\% \mathrm{E}$ & $80 / 80$ & $\% \mathrm{E}$ & $80 / 60$ & $\% \mathrm{E}$ & $60 / 60$ & $\not / E E$ \\
\hline \multicolumn{13}{|c|}{ Same Judgments } \\
\hline 1 & 461 & 3 & 475 & 0 & 543 & 11 & 468 & 3 & 511 & 3 & 476 & 3 \\
\hline 2 & 444 & 1 & 477 & 2 & 504 & 11 & 442 & 1 & 496 & 7 & 456 & 0 \\
\hline 3 & 384 & 6 & 428 & 8 & 458 & 11 & 403 & 0 & 454 & 7 & 423 & 2 \\
\hline 4 & 386 & 7 & 415 & 8 & 474 & 28 & 408 & 3 & 429 & 18 & 408 & 14 \\
\hline 5 & 415 & 0 & 421 & 3 & 485 & 23 & 408 & 1 & 454 & 1 & 427 & 1 \\
\hline 6 & 461 & 6 & 510 & 9 & 546 & 9 & 465 & 3 & 494 & 7 & 485 & 9 \\
\hline Mean RT & 425 & & 459 & & 502 & & 432 & & 473 & & 446 & \\
\hline \% Error & 3.7 & & 5.0 & & 15.5 & & 2.0 & & 7.0 & & 5.0 & \\
\hline \multicolumn{13}{|c|}{ Different Judgments } \\
\hline 1 & 532 & 12 & 553 & 9 & 512 & 11 & 530 & 7 & 516 & 8 & 565 & 10 \\
\hline 2 & 480 & 4 & 485 & 2 & 501 & 6 & 489 & 3 & 495 & 6 & 495 & 16 \\
\hline 3 & 447 & 7 & 424 & 3 & 428 & 3 & 456 & 10 & 458 & 8 & 498 & 17 \\
\hline 4 & 435 & 16 & 419 & 11 & 395 & 8 & 429 & 13 & 386 & 7 & 413 & 11 \\
\hline 5 & 453 & 8 & 444 & 13 & 442 & 2 & 461 & 7 & 447 & 10 & 468 & 22 \\
\hline 6 & 502 & 9 & 491 & 9 & 509 & 8 & 517 & 12 & 501 & 6 & 510 & 11 \\
\hline Mean RT & 475 & & 469 & & 465 & & 480 & & 467 & & 491 & \\
\hline$\%$ Error & 9.2 & & 8.0 & & 6.3 & & 8.7 & & 7.2 & & 14.0 & \\
\hline
\end{tabular}

to see if matching a test stimulus with one already stored in memory would yield the same pattern of results as in the simultaneous presentation of Experiment I. One possibility is that the change from simultaneous to successive presentation may induce a reorganization of matching strategies in the subject. For example, successive presentation may encourage the subject to look for sameness and make "different" judgments by default. If this were so, then we would expect the presence of relative size differences to have time-cost consequences of equal magnitude for both "same" and "different" judgments.

A second reason for employing successive presentation of stimuli was simply to observe whether absolute size was coded as part of the description of the stimulus stored in memory. Pylyshyn (1973) contends that the picture metaphor underlying recent theoretical discussions of "visual imagery" is misleading, and that it would be more profitable to think of functional images that are selective, rather than exhaustive, representations of the original visual stimulus. It seems entirely plausible that subjects may code the stimulus as a size-free structural description, in which case there would be no observable effects of differences in relative size between the two stimuli.

\section{Method}

Stimuli. The stimuli were computer-generated random patterns whose size varied only along the vertical axis. Stimulus 1 was presented for $500 \mathrm{msec}$; this was followed by a $750-\mathrm{msec}$ mask, then by Stimulus 2 . The second stimulus terminated when the subject made a response. The degree of visual angle subtended by the stimulus was approximately $60 \%$ larger than in Experiment 1. Some examples of the stimuli and mask can be seen in Figure 2. All other aspects of the procedure were identical to that of Experiment I, except that subjects received 50 practice trials and served in only one session.

Subjects. The subjects were five males and two females from the same population as in Experiment I. Four of the subjects were new, while the other three had taken part in Experiment I. All the subjects served without pay.

\section{Results}

The data from the practice trials and those trials on which errors were committed were excluded from the analysis. The remaining data can be seen in Table 2 .

An analysis of variance indicated that the main effects of Size and Response Type were significant, and that the interaction of Size by Response Type was again significant $\left[\mathrm{F}(5,30)=21.9, \mathrm{p}<.01, \mathrm{MS}_{\mathrm{e}}=278\right]$. It is clear from Table 2 that (a) absolute size is coded as part of the description of the first stimulus stored in memory and (b) that, again, there is little effect of relative size difference on "different" judgments.

\section{DISCUSSION}

The expectation that the presence of differences in relative size would not result in increasing and equal time costs to both types of response judgments appears to have been confirmed. This seems a particularly striking result in the face of classification studies where preprocessing required to filter experimentally induced
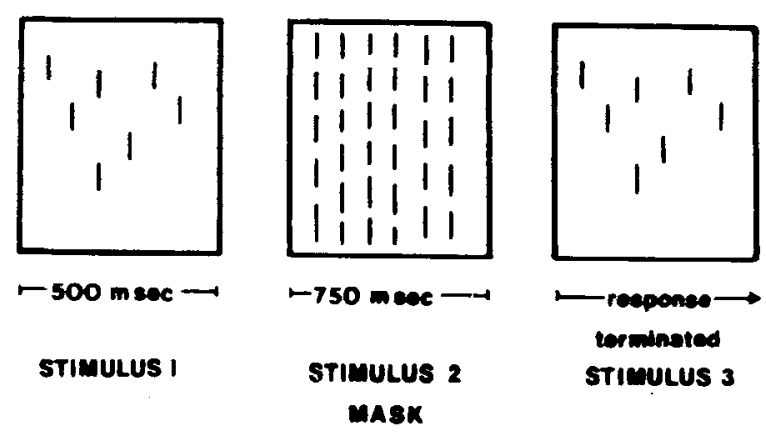
Fig
mask. 
Table 2

Mean Reaction Times and Error Rates According to Conditions

\begin{tabular}{|c|c|c|c|c|c|c|c|c|c|c|c|c|}
\hline Subjects & $100 / 100$ & $\% \mathrm{E}$ & $100 / 80$ & $\% \mathrm{E}$ & $100 / 60$ & $\% \mathrm{E}$ & $80 / 80$ & $\% \mathrm{E}$ & $80 / 60$ & $\% \mathrm{E}$ & $60 / 60$ & $\% \mathrm{E}$ \\
\hline \multicolumn{13}{|c|}{ Same Judgments } \\
\hline 1 & 441 & 0 & 481 & 7 & 494 & 23 & 449 & 0 & 447 & 3 & 412 & 7 \\
\hline 2 & 430 & 0 & 417 & 0 & 510 & 17 & 397 & 0 & 434 & 3 & 391 & 0 \\
\hline 3 & 417 & 0 & 448 & 0 & 507 & 7 & 383 & 0 & 432 & 0 & 377 & 0 \\
\hline 4 & 430 & 0 & 445 & 3 & 564 & 37 & 408 & 0 & 447 & 17 & 411 & 0 \\
\hline 5 & 539 & 3 & 572 & 7 & 624 & 13 & 518 & 0 & 570 & 3 & 507 & 0 \\
\hline 6 & 484 & 10 & 489 & 7 & 622 & 13 & 471 & 3 & 535 & 13 & 455 & 0 \\
\hline 7 & 478 & 0 & 463 & 7 & 536 & 7 & 447 & 10 & 474 & 7 & 454 & 0 \\
\hline Mean RT & 448 & & 459 & & 534 & & 428 & & 469 & & 419 & \\
\hline$\%$ Error & 2 & & 4 & & 17 & & 3 & & 7 & & 1 & \\
\hline \multicolumn{13}{|c|}{ Different Judgments } \\
\hline 1 & 500 & 13 & 476 & 3 & 507 & 0 & 485 & 3 & 476 & 7 & 487 & 13 \\
\hline 2 & 498 & 13 & 476 & 10 & 493 & 20 & 479 & 3 & 501 & 3 & 514 & 0 \\
\hline 3 & 535 & 10 & 490 & 13 & 557 & 17 & 504 & 3 & 548 & 10 & 499 & 10 \\
\hline 4 & 504 & 13 & 445 & 7 & 474 & 23 & 494 & 10 & 506 & 3 & 495 & 37 \\
\hline 5 & 652 & 10 & 634 & 17 & 652 & 13 & 628 & 7 & 656 & 10 & 672 & 7 \\
\hline 6 & 560 & 20 & 538 & 10 & 581 & 7 & 573 & 20 & 561 & 10 & 557 & 13 \\
\hline 7 & 536 & 10 & 536 & 13 & 543 & 10 & 527 & 13 & 517 & 3 & 560 & 10 \\
\hline Mean RT & 541 & & 514 & & 544 & & 527 & & 538 & & 541 & \\
\hline \% Error & 13 & & 10 & & 13 & & 9 & & 7 & & 13 & \\
\hline
\end{tabular}

visual noise results in time costs that are independent of response type (e.g., Bracey, 1969; Nickerson, 1975; Sternberg, 1967).

If it is assumed that normalization and comparison stages are sequential and additive, then it follows that only those processes responsible for "same" decisions operate on the output of a normalization stage. This suggests that, in addition to the existence of separate and concurrent analyses for "same" and "different" decisions that have been postulated by Bamber (1969), Egeth and Blecker (1971), Kreuger (1973), Nickerson (1969, 1971), Sekuler (1965), and others, there also exist separate representations upon which such analyses are performed. This does not seem implausible in view of those laterality studies implicating specialization of function for different components of the same task; for example, Egeth and Epstein (1972) reported data consistent with the speculation that the left hemisphere is specialized for sameness detection and the right hemisphere for difference detection.

\section{"Different" Judgments}

One way of accounting for "different" judgment RTs is covered by a class of models commonly referred to as deadline models (e.g., Nickerson, ${ }^{1}$ 1969, 1971; Sekuler, 1965). In these models one decision (e.g., "different") may be emitted by a clock that simply counts time, while the remaining decision is controlled by a counter that accumulates evidence. If enough evidence is accumulated, the counter emits a response, whereas if the clock has counted to some time $t$ before the counter has accumulated sufficient evidence, then the clock controls a response. At first approximation, a clock that responds "different" when a deadline has been reached would seem to offer a ready explanation for the failure of relative size differences to affect "different" latencies. So long as the deadline is set sufficiently late to allow time for both normalization and those subsequent processes responsible for "same" decisions to operate, the model presents no problems. The main difficulty is that the deadline model predicts that, on the average, the "different" judgments should be slower than the slowest condition containing correct "same" judgments, and this is clearly not the case. Tables 1 and 2 indicate that the "different" judgments are, on the average, too fast. This comparison is somewhat obscured by the fact that response hand was not a balanced factor, but it seems implausible that controlling for this variable is likely to make "different" judgments as much slower relative to "same" judgments as the model requires, especially since the "different" response was always made by the left hand of right-handed subjects.

Reservations have been expressed (Garner, 1970, 1974; Garner \& Felfoldy, 1970; Lockhead, 1966, 1972; Nickerson, 1972; Rabbit, 1971) about the rather arbitrary decomposition of stimuli into feature lists of dimensions on the basis of experimenter intuitions for the purposes of testing hypotheses that related to the question of serial or parallel processing. Garner's point is that the distinction between separable and inseparable or integral dimensions logically proceeds the serial/ parallel processing issue. When stimulus dimensions are integral ones, the serial/parallel issue may not be applicable since, while a stimulus may be multidimensional insofar as one is able to list its size, brightness, and hue, such considerations need not relate to the possibility that the stimulus is processed as a unidimensional whole. While the integrality hypothesis seems most forceful when applied to stimuli that are the same in all respects (e.g., when both stimuli share the same color, 
form, and size), it may be the case that some form of analysis that views the stimulus analytically must be invoked when irrelevant attributes that differ in state are present.

If this should be the case, a second model within which "different" judgments may fail to be influenced by relative size differences is based upon an ordered comparison process. Differences in relative size would not affect "different" judgment latencies if feature examination is an ordered process such that relevant attributes (e.g., shape) are examined prior to irrelevant attributes (e.g., size) [as in the serial and self-terminating model that Egeth (1966) has considered], nor if the processing mode is parallel and self-terminating [as suggested by Hawkins (1969)], but distributes its processing capacity unequally between different sets of analyzers such that relevant feature analyzers are allocated more capacity and thus finish first. A third possibility is that the difference-detecting mechanism operates upon a representation which consists of a structural description which is selective to the extent that the description is size free; i.e., it only describes the way in which line segments are connected to form a shape.

\section{"Same" Judgments}

An alternative to the normalization hypothesis might ascribe the effects of relative size differences on "same" judgments to an inability on the part of the "same" analyzing mechanism to gate irrelevant information. In this model it is not the operation of a normalization stage that incurs time costs when a size difference is present, but the time to decide about a correct response in the face of conflicting evidence about sameness.

One view that has been taken (Hawkins \& Shigley, 1972) suggests that the operations governing "same" shape matching of identical stimuli occur at a lower level in the perceptual system than those operations that are required when irrelevant dimensions whose values differ between stimuli are present. Hawkins and Shigley have argued that extensive contact with memory is not a logical requirement when irrelevant dimensions agree in state with relevant dimensions. Since here there is no evidence at all indicating a difference, the response "same" may be triggered without regard to the distinction between relevant and irrelevant dimensions. Thus, when all the evidence agrees, it is a moot point as to whether the relevant dimension may be said to control the response. However, when matching operations produce a mismatch with respect to any stimulus dimension, it becomes necessary to distinguish between rele. vant and irrelevant dimensions in order to produce a correct response. Hawkins and Shigley (1972) have suggested that this interrogation of memory is accomplished by a serial scan of a list that details which attributes are relevant and which are irrelevant.
This model predicts that the discriminability of the difference on the differing irrelevant dimension should be inversely related to the amount of time it delays a successful "same" judgment. The larger the difference in size between stimuli, the sooner this difference should produce a mismatch; consequently, large differences should produce less time costs than small differences, because the interrogation of memory necessary to distinguish between relevant and irrelevant dimensions is contingent upon the detection of a mismatch. The opposite occurs; the larger the size difference between stimuli, the slower the "same" response is.

A more satisfactory possibility is that the SAME system employs a set of hierarchically arranged tests. An early level of such tests may correspond to Neisser's (1967) preattentive stage of processing and yield responses on the basis of an "identity reporter" (Bamber, 1969), a holistic "template" match (Marcel, Note 2), or by recourse to structural diagnostics such as bilateral symmetry (Fox, 1975). Any failure of this level to evoke a response has two consequences. One is to enable tests for specific properties, such as shape or other taskdefined relevant attributes. The second is that an early detection of a difference causes the SAME system to reset its decision criterion such that a higher level of evidence on any feature test is required before the system can be persuaded to respond "same." An increasing RT function can be generated provided large size differences result in larger criterion shifts than do small size discrepancies. This explanation is a simple one, and, aside from being face plausible, it also dispenses with the necessity of postulating yet another processing "stage" such as normakization. It is aiso similar (perhaps indistinguishable) to one proposed by Seymour (1975) to account for certain kinds of same-different effects.

The conclusions that emerge from these experiments are: (a) that the failure of relative size differences to slow "different" judgments is not due to nominal matching, (b) that "different" judgments do not result from the operation of a deadline time limit, and (c) nor do they result from comparing internal representations which have previously undergone a normalization process. On the other hand, "same" judgments may either be preceded by a time-consuming analog scaling operation, when the stirnuli are discrepant with respect to size, or simply be slower because early detection of a size difference causes a shift in the decision criteria associated with the "same" counter, such that the amount of evidence required to evoke a response is increased.

A further line of evidence that appears consistent with the criterion shift explanation, but not immediately with the normalization hypothesis, comes from the finding that, in a same-different task with words and nonwords, there is a smaller effect due to a size difference when words are matched than when nonwords are 
matched (Besner \& Coltheart, 1975). Posner (1969) and Posner and Mitchell (1967) have suggested that normalization depends upon operations which can be performed within the visual system and need not require contact with past experience. If normalization is the early stage that precedes visual comparisons for both words and nonwords, then it might be expected that the effects of size and wordness would be additive rather than interactive. On the other hand, if wordness acts to decrease the criterion on the amount of evidence necessary for successful visual matching, as has been suggested by Baron (1975), then the interaction is not surprising.

Finally, a recent paper by Bundesen and Larsen (1975) highlights the importance of further investigations to specify the ways in which subtle changes in the task might alter the nature of the comparison process. Bundesen and Larsen performed an experiment that was almost identical to those reported here. However, they found that the function relating RT to the magnitude of the size difference between stimuli was an increasing linear one with identical slopes for both correct "same" and correct "different" decisions. On the face of it, this would appear to offer strong support for the existence of a normalization stage.

The important difference between their experiment and the present ones is that the stimuli requiring a "different" classification in the former experiment consisted of identical stimuli that were rotated $180 \mathrm{deg}$ relative to each other. It is not at all clear that what is involved in determining whether identical stimuli share either the same or a different orientation is the same process as determining whether or not two stimuli have the same shape. One possibility is that in this task the comparison process operates in such a manner that "different" responses are made by default, rather than by the detection of a difference. If a "different" classification is made on the basis of a time-elapsed period that failed to generate a "same" response, then any process that retards a "same" classification (such as a decision criteria shift resulting from an early similarity judgment prior to matching) will also retard "different" classifications by an equal amount. This suggests that it might be premature to assume that Bundesen and Larsen's (1975) results unequivocally support a normalization hypothesis to the exclusion of all other explanations. At the very least, the generality of the normalization explanation is constrained by the present results.

Taken together, then, it would not yet appear to be a necessary interpretation that observers cope with size discrepancies when making shape judgments by first scaling the stimuli so that they are equally sized. This is not to contend that mental size scaling never occurs, but rather that the experiments reported here do not exclusively support such an interpretation. It is tempting to speculate as to why normalization might not even be the optimal strategy in the case of simultaneously presented stimuli. One possibility is that attempts to manipulate, rather than simply analyze, visual informa tion may be considerably hampered by the continuing visual input of the original form.

\section{REFERENCE NOTES}

1. Besner. D., \& Coltheart. M. Asymmetry in binan classification: The effects of relative size on reaction time. Paper presented at Canadian Psychological Association, 1974, Windsor, Canada.

2. Marcel. A. J. Serial and parallel processing in pattern recognition. Paper presented at the meeting of the Experimental Psychology Society, London, 1969.

\section{REFERENCES}

BAMBER, D. Reaction time and error rates for same-different judgments of multidimensional stimuli. Perception \& Psychophysics, 1969, 6, 169-174.

BAron, J. Successive stages in word recognition. In P. M. A. Rabbitt \& S. Dornic (Eds.), Attention and performance V. London: Academic Press, 1975.

Besner, D., \& Coltheart, M. Same-different judgments with words and nonwords: The differential effects of relative size. Memory \& Cognition, 1975, 3, 673-677.

BraCEY, E. W. Two operations in character recognition: A partial replication. Perception \& Psychophysics, 1969. 6. $357-360$.

Bundesen. C., \& LARSEN, A. Visual transformation of size. Journal of Experimental Psychology: Human Perception and Performance, 1975, 1, 214-220.

Corcoran, D. W. J., \& Besner, D. Application of the Posner technique to the study of size and brightness irrelevancies in letter pairs. In P. M. A. Rabbitt \& S. Dornic (Eds.), Attention and performance V. London: Academic Press, 1975.

Egeth, H. Paraliel vs. serial processes in multidimensional stimulus discrimination. Perception \& Psychophysics, 1966. 1, 245-252.

Egeth, H., \& Blecker, D. Differential effects of familiarity on judgments of sameness and difference. Perception \& Psychophysics, 1971, 9, 321-326.

Egeth, H., \& Exstein, J. Differential specialization of the cerebral hemispheres for the perception of sameness and difference. Perception \& Psychophysics, 1972, 12, 218-220.

Fox, J. The use of structural diagnostics in recognition. Journal of Experimental Psychology, Human Perception and Performance, 1975, 1, 56-67.

GARNER, W. R. The stimulus in information processing. American Psychologist, 1970, 25, 350-358.

GARNER, W. R. Information processing and structure. Potomac, Md: Lawrence Erlbaum, 1974.

Garner, W. R., \& Felfoldy, G. L. Integrality of stimulus dimensions in various types of information processing. Cognitive Psychology, 1970, 1, 225-241.

Hawxins, H. L. Parailel processing in complex visual discrimination. Perception \& Psychophysics, 1969, 5, 56-64.

Hawkins, H. L., \& SHIGlEY, R. H. Irrelevant information and processing mode in speeded discrimination. Journal of Experimental Psychology. 1972. 96, 389-395.

KREUGER, L. E. Effect of irrelevant surrounding material on speed of same-different judgements of two adjacent letters. Journal of Experimental Psychology, 1973, 98, 252-259.

LoскнEAD, G. R. Effects of dimensional redundancy on visual discrimination. Journal of Experimental Psychology, 1966. 72, 95-104.

Lockhead, G. R. Processing dimensional stimuli: A note. Psychological Review, 1972, 79. 410-419.

NeISSER, U. Cognitive psychology. New York: AppletonCentury-Crofts, 1967.

Nickerson, R. S. "Same"-"different" response times: A model and a preliminary test. In W. G. Koster (Ed.), 
Attention and performance 11 . Amsterdam: North Holland, 1969. Pp. 257-275.

Nickerson. R. S. "Same"-"different" response times: A further test of a counter and clock model. Acta Psychologia, 1971, 35, 112-127.

Nickerson, R. S. Binary classitication reaction time: A review of some studies of human information processing capabilities. Psychonomic Monograph Supplements, 1972, 4. 17.

Nickerson. R. S. Effects of correlated and uncorrelated noise on visual pattern matching. In P. M. A. Rabbitt \& S. Dornic (Eds.). London: Academic Press, 1975.

Posner. M. I. Abstraction and the process of recognition. In G. Bower (Ed.), Advances in learning. New York: Academic Press, 1969.

Posner, M. I. Cognition: An introduction. Glenville, Ill: Scott, Foreman, 1973.

Posner, M. 1., \& Mitchell, R. F. Chronometric analysis of classification. Psychological Review', 1967, 74, 392-409.

Pylyshyn, Z. W. What the mind's eye tells the mind's brain: A critique of mental imagery. Psychological Bulletin, 1973. 80. 1 -24.

Rabitt, P. M. A. Times for the analysis of stimuli and for the selection of responses. British Medical Bulletin, 1971, 27, 259-265.

Sekuler, R. Signal detection, choice response times, and visual backward masking. Canadian Journal of Psychology, $1965,19,118-132$.

SeKuler, R., \& Nash, D. Speed of size scaling in human vision. Psychonomic Science, 1972, 27, 93-94.

Seymour, P. H. K. Semantic equivalence of verbal and pictorial displays. In A. Kennedy \& A. Wilkes (Eds.), Studies in long-term memory. New York: Wiley, 1975.

ShePard, R., \& METZler, J. Mental rotation of three dimensional objects. Science, 1971, 171, 701-703.

STERnBerg, S. Two operations in character recognition. In W. Wathen-Dunn (Ed.), Models for the perception of speech and form. Cambridge: M.I.T. Press, 1967.

TAYLOR, R. L. Reading spatially transformed digits. Journal of Experimental Psychology, 1972, 96, 396-399.

\section{NOTE}

1. Nickerson's version of the deadline model has the clock in control of the "same" response and the counter in control of the "different" response, rather than vice versa.

(Received for publication October 9, 1975; revision accepted January $14,1976$. ) 